\title{
Structural Analysis on the Block Lifting in Shipbuilding Construction Process
}

\author{
Muhammad Nurul Misbah ${ }^{1,{ }^{*}}$, Septia Hardy Sujiatanti ${ }^{1}$, Dony Setyawan ${ }^{1}$, Rizky Chandra \\ Ariesta $^{1}$, and Satriyo Rahmadianto ${ }^{2}$ \\ ${ }^{1}$ Department of Naval Architecture, Institut Teknologi Sepuluh Nopember, Surabaya, Indonesia \\ ${ }^{2}$ PT Dok dan Perkapalan Surabaya (Persero), Surabaya, Indonesia
}

\begin{abstract}
Deformation is unavoidable in some stages of the ship production process. Deformation occurs when the blocks are lifted in an erroneous eye pad position. The aim of this study was to determine behaviour of the ship structures during assembly and lifting process. A typical tanker was used as the basic structural shape. The bottom structures was modeled to be analyzed. In this study, deformations and stresses on the bottom structures during the block lifting are investigated using the finite element method. The deformations and stresses are evaluated and critical condition detected. The preferable block lifting method with the minimum distortion on the bottom structures of tanker is proposed.
\end{abstract}

\section{Introduction}

Ship, as a complex product, was divided correspond to different criteria. One of the important criteria is spatial criterion. This criterion is important to the production phase and it is dependent on the technological possibilities of the shipyard. Basic of spatial division of the ship, widely used for most types of ships, is division on macro spaces i.e. after peak, machinery space, cargo space, fore peak, and superstructure. Division in macro space also well-known as a block or grand block system in shipbuilding process.

Block assembly is the process in which the hull of a ship is built by joining blocks together. It is also called hull assembly. Blocks are large welded steel structures that are typically manufactured as single part. When a block is ready, it is typically arranged near the launching place, lifted to the launching place, and welded to other blocks there. Block assembly in shipbuilding is a unique phase when shipbuilding is compared with the normal type of mechanical engineering production [1].

Currently, many shipyards use the method of block assembly in the shipbuilding process. This method makes the ship to be produced faster than the conventional method of shipbuilding. In the method of block assembly, ship production process is

${ }^{*}$ Corresponding author : mnmisbah5@gmail.com 
done by combining the blocks into a large block or part of the ship [2]. The problem occurs when the process of block assembly is after the lifting of the block. The lifted block will changes shape or deformation [3].

In this paper, the bottom structures of typical tanker is carried out to be analyzed. The typical bottom structures of tanker are given in Fig.1. The analysis of block lifting on bottom structures of tanker using the finite element method. The lifting process of the tanker bottom structure block was simulated by install some eye plates or eye pads on portside block and center block with various position of eye pads. The goal of the finite element analysis was to successfully predict the effect of block lifting in shipbuilding process with various position of eye pads. The optimum of eye pads position can be assumed based on the minimum deformation resulted from lifting process.

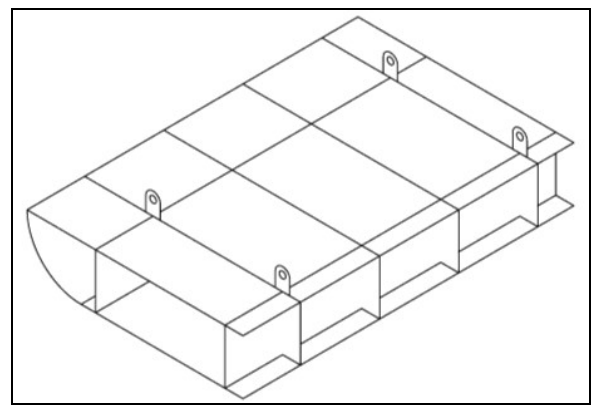

(a)

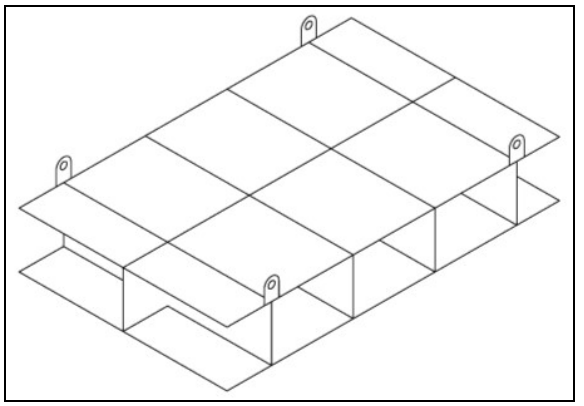

(b)

Fig. 1. Bottom structures of tanker at portside block (a) and center block (b)

\section{Shipbuilding Production Process}

Ship production is a very difficult job as it covers many processes. A ship is produced by performing thousands of work activities. To produce ships, various types of workstations are required. Each workstation has a duty to ship production.

Assembly is one of the most common operations in the production process. This involves combining parts in a separate and inseparable way. As a result, a complicated product called assembly is made. The singularity of the ship's structure is connected with a large number of elements [4]. The hull production consists of combining with the welding method in an inseparable way. The hull, as the final assembly, is a unified whole. This is a distinctive feature that distinguishes the hull assembly from mechanical assemblies. In the case of the shipbuilding process, the component may be called a subassembly, i.e. a previously assembled structure.

Components can be assembled in different sequences called sequences. Each assembly sequence leads to the same result - the final structure. However, the sequence differs in terms of the value of many criteria, for example: implementation difficulties, energy costs, employee safety, qualifications required for welders, total execution time, etc. The selection of the best sequence is therefore a multi-purpose optimization problem. The whole class of problem types and their settlement methods are called assembly sequence planning (ASP). 


\section{Finite Element Model}

A typical bottom structure block is considered. The block size and topology is defined by shipbuilding assembly practice and drawings of the ship, designed and produced in a shipyard. The bottom portside block dimensions are $30.5 \times 12 \times 6$ meters (width $\mathrm{x}$ length $\mathrm{x}$ height). Block consists of bottom and inner bottom structures. Bottom structure consists of bottom plate, bottom longitudinal, and bilge plate. Inner bottom structure consists of inner bottom plate and inner bottom longitudinal. Plate floor, bottom center girder and bottom side girder are installed between bottom plate and inner bottom plate.

The finite element analysis is carried out to analyze the stress and maximum deformation during block lifting process. The bottom structure of tanker was modeled using finite element software package. In the analyses, three-dimensional finite element models were developed. Eight node shell element having six degrees of freedom per node was used to model the steel plates and three node beam element with six degrees of freedom per node was used to model the stiffeners [5]. The bottom structure models were analyzed for various eye pad position. The variations of eye pad positions for portside block are shown in Fig. 2.

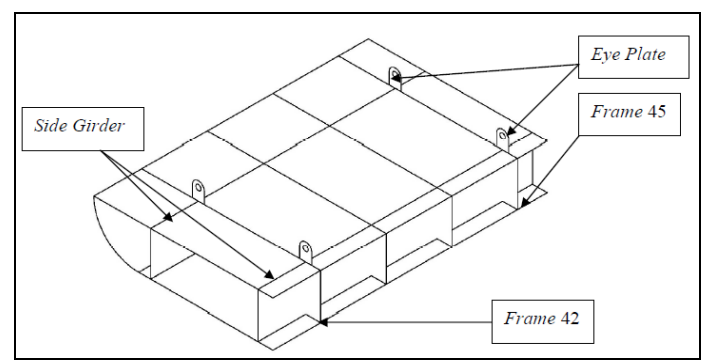

(a) $1^{\text {st }}$ case

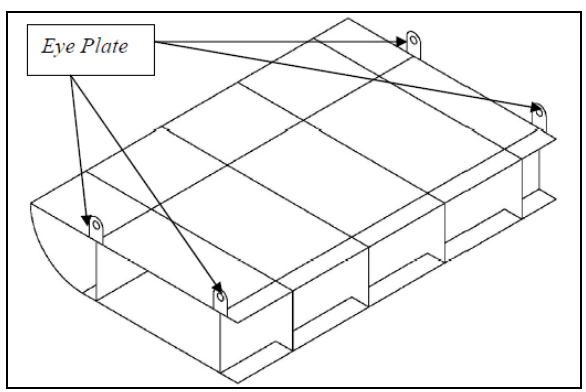

(c) $3^{\text {rd }}$ case

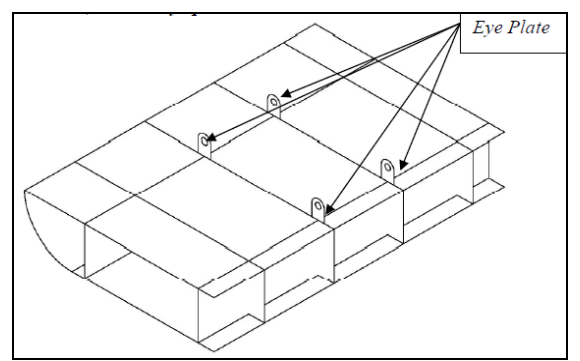

(b) $2^{\text {nd }}$ case

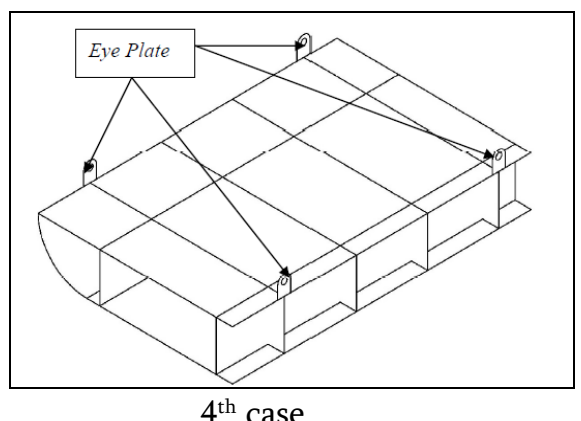

$4^{\text {th }}$ case

Fig. 2. Eye pad position at the portside block

The variations of eye pad positions for center block are shown in Fig. 3. 


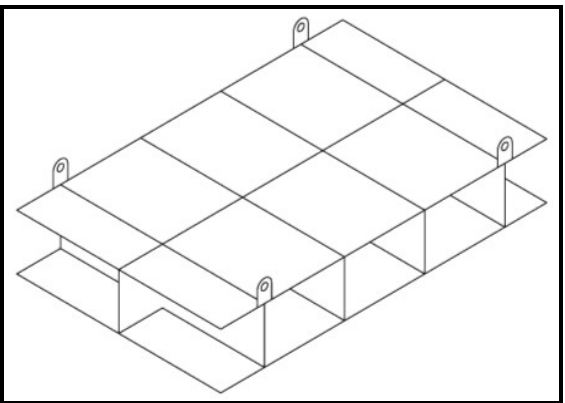

(a) $1^{\text {st }}$ case

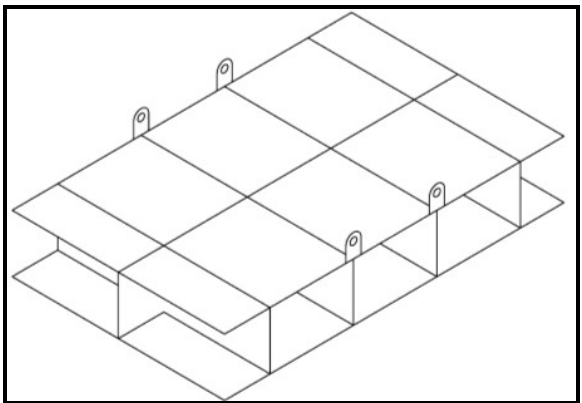

(b) $2^{\text {nd }}$ case

Fig. 3. Eye pad position at the center block

\section{Analysis of the Block Lifting}

By lifting the block, all the weight will be transferred to the crane through, in this case, four eye pads or lifting pads. The boundary conditions fix all the lifting pads. Caused by that, the weight will cause displacement mostly in the vertical direction, i.e. the y-axis. Fig. 4 presents deformation of the bottom structure when the portside block is being lifted by various eye pads positions.
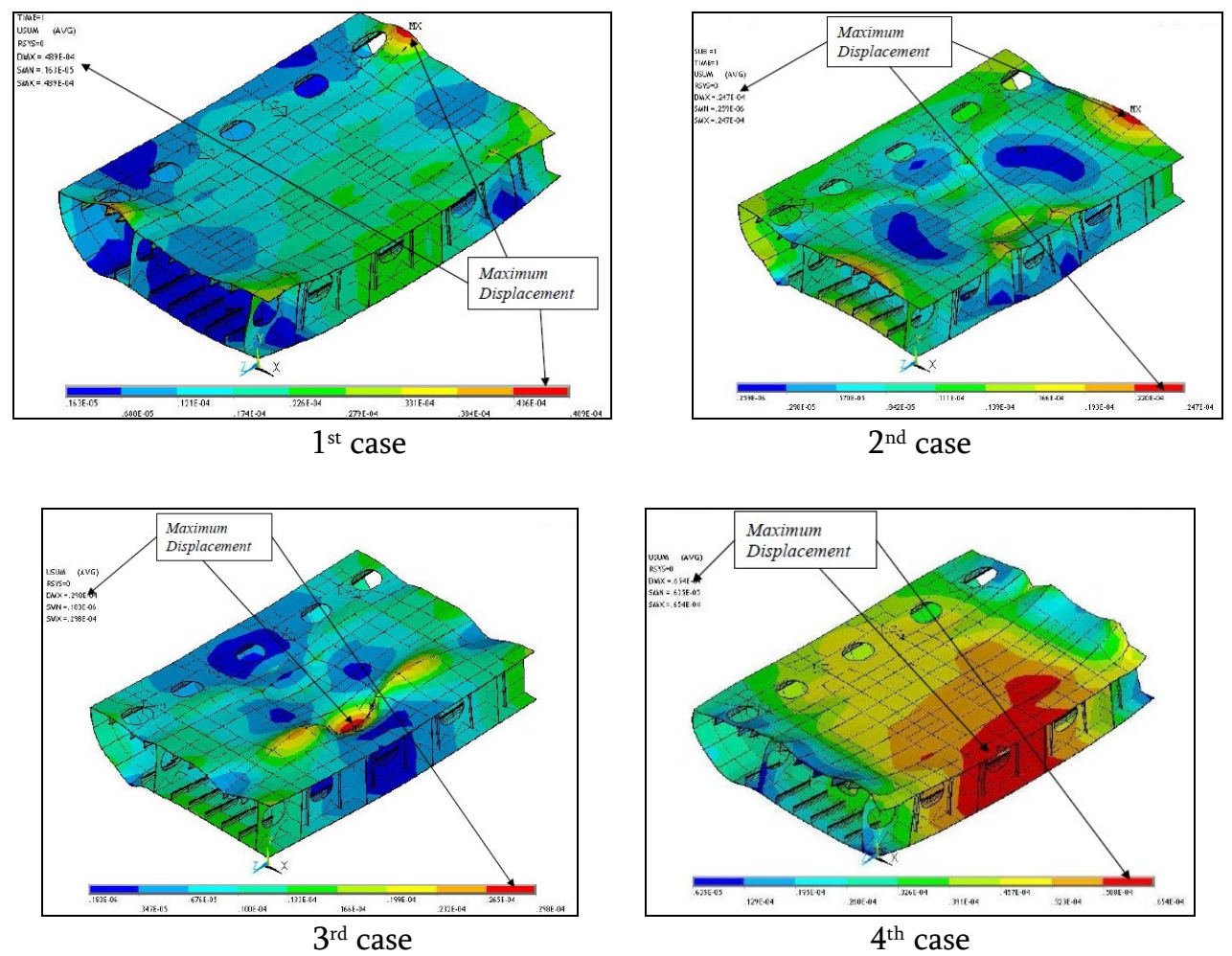

Fig. 4. Deformation at the portside block 
The deformation of the bottom structure when the center block is being lifted by various eye pads positions are shown in Fig. 5.
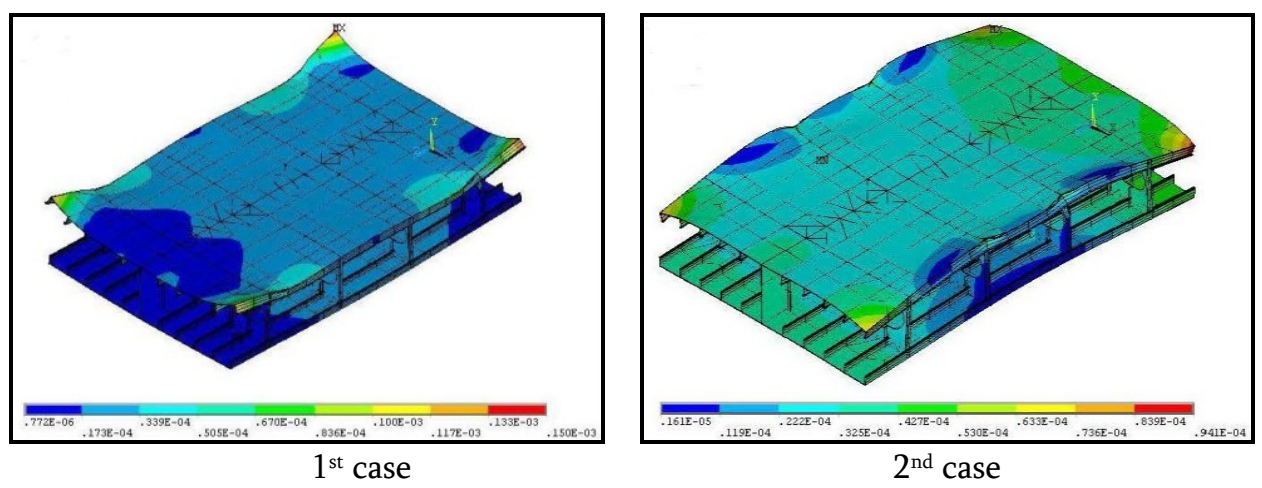

Fig. 5. Deformation at the center block

\section{Result}

The simulation results of bottom structures with various eye pad positions on portside block show the maximum deformation. The finite element simulation results have shown in Fig. 4. and Fig. 5. The maximum deformation on the portside block of bottom structure for various eye pad positions are given in Table 1.

Table 1. Maximum deformation for various eye pad at the portside block

\begin{tabular}{|c|c|}
\hline Type & Max. Deformation $[\mathrm{mm}]$ \\
\hline $1^{\text {st }}$ case & 0.049 \\
\hline $2^{\text {nd }}$ case & 0.025 \\
\hline $3^{\text {rd }}$ case & 0.030 \\
\hline $4^{\text {th }}$ case & 0.065 \\
\hline
\end{tabular}

The maximum deformation on the portside block of bottom structure for various eye pad positions are given in Table 2.

Table 2. Maximum deformation for various eye pad at the center block

\begin{tabular}{|c|c|}
\hline Type & Max. Deformation $[\mathrm{mm}]$ \\
\hline $1^{\text {st }}$ case & 0.0412 \\
\hline $2^{\text {nd }}$ case & 0.0928 \\
\hline
\end{tabular}




\section{Summary}

According to the analysis results presented in Fig. 4 and Fig. 5 also presented in Table 1 and Table 2, it can be concluded that the lowest deformation occur on the block of bottom structure is $2^{\text {nd }}$ case i.e. $0.025 \mathrm{~mm}$ for portside block and $1^{\text {st }}$ case i.e. 0.0412 $\mathrm{mm}$ for center block. Therefore, the variation of eye pad position can be recommended for block lifting process on bottom block of tanker is $2^{\text {nd }}$ variation for portside block and $1^{\text {st }}$ variation for center block.

\section{References}

[1] Varghese, R., Yoon, D. Y, Shipbuilding erection network optimization: A TSP method, Journal of Ship Production, 22, 3, 139-146, (2006)

[2] R. R. Iwańkowicz, Integration Of Ship Hull Assembly Sequence Planning, Scheduling And Budgeting, Advances in Science and Technology Research Journal, Volume 9 No. 25 pp 12-19, (2015)

[3] V Adan, C Alexandra, B Juan, S Hishashi, Numerical Analysis of Straightening Process of Thin Plate Structures by Elastic FEM Based on the Inherent Straint Method, Transaction of JWRI vol.41 (2012)

[4] M Ozkok, Risk Assessment In Ship Hull Structure Production Using FMEA, Journal of Marine Science and Technology, DOI: 10.6119/JMST-013-0222-1

[5] S H Sujiatanti, A Zubaydi, A Budipriyanto, Finite Element Analysis of Ship Deck Sandwich Panel, The 1st SENTA International Conference on Marine Technology, ITS Surabaya (2016) 